\title{
Fabrication of Ag Np-coated wetlace nonwoven fabric based on amino-terminated hyperbranched polymer
}

https://doi.org/10.1515/ntrev-2019-0009

Received Feb 21, 2019; accepted Apr 12, 2019

\begin{abstract}
To prepare antibacterial fabrics with simple approach, wood pulp/viscose fibers and amino-capped silver nanoparticles (Ag NPs) solution were utilized to form Ag Nps-coated wetlace nonwove fabric. Characterization of the Ag Nps and prepared wetlace nonwoven fabric was performed in virtue of TEM, UV-vis, XRD, ICP-AES, FESEM, EDS mapping and antibacterial test. FESEM and EDS characterizations demonstrated the hierarchical and uniform coating of high-density Ag NPs on wood pulp fibers, and antibacterial test indicated the excellent antibacterial activity of prepared wetlace nonwoven fabric.
\end{abstract}

Keywords: Wetlace; fiber technology; sliver nanoparticles; antibacterial activity

\section{Introduction}

The wetlace nonwoven fabric was formed by wet-laid and spunlace reinforcement process $[1,2]$. Compared with traditional fabrics, wetlace nonwoven fabric exhibits high generation speed and possess sufficient softness, flexibility and conformability, making it widely applied in moist wipes and biomedical field [3-6]. The traditional wetlace

\footnotetext{
${ }^{\star}$ Corresponding Author: Wei Zhang: National \& Local Joint Engineering Research Center of Technical Fiber Composites for Safety and Health, School of Textile and Clothing, Nantong University, Nantong 226019, China; Email: zhangwei@ntu.edu.cn; Tel.: $+8651385012837$

Guangyu Zhang: National \& Local Joint Engineering Research Center of Technical Fiber Composites for Safety and Health, School of Textile and Clothing, Nantong University, Nantong 226019, China; College of Chemical and Biological Engineering, Zhejiang University, Hangzhou, Zhejiang 310027, China

Dao Wang, Yao Xiao, Jiamu Dai, Yu Zhang: National \& Local Joint Engineering Research Center of Technical Fiber Composites for Safety and Health, School of Textile and Clothing, Nantong University, Nantong 226019, China
} ๑ Open Access. () 2019 G. Zhang et al., published by De Gruyter. (cc) BY License nonwovens often contain entangled synthetic fibers, leading to difficulty in degradation. The ever-increasing consumer and industrial demand for environmentally friendly products makes natural raw materials popular, such as cotton, viscose, wood pulp, polylactic acid, and chitosan [710].

Compared to other metal antibacterial materials, sliver nanoparticles (Ag NPs) exhibit an efficient antibacterial activity against a broad spectrum of bacteria including Escherichia coli (E.coli), Staphylococcus aureus (S.aures) and Candida albicans, thereby enjoying an extensive application in biomedical field. Surface coating of biomedical fibers with Ag NPs has been extensively studied in term of the utility in biomedical field [11-17]. Several methods can be used to make nanoparticle coatings on biomedical fabric, such as chemical deposition, spray pyrolysis, low plasma, and dip coating. Nevertheless, coating Ag NPs on the surface of fabric is challenging as related techniques require sophisticated equipment, large amount of time as well as high cost [18-24].

Recently, hyperbranched polymers and dendrimers have been widely applied to the synthesis of nanoparticles. In our previous study, an amino-terminated hyperbranched polymer (HSDA)was synthesized (Figure 1).

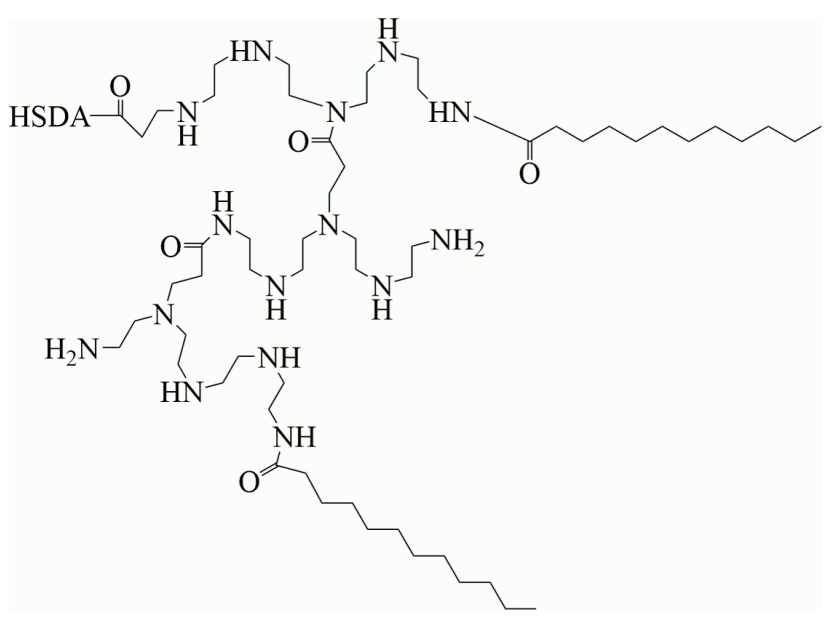

Figure 1: Schematic description of the HSDA molecule structure. 
HSDA was used as template to synthesize and disperse $\mathrm{ZnO}$ nanoparticles and also served as a binder to impart and fix the $\mathrm{ZnO}$ nanoparticles on the bamboo fabric for generating antimicrobial and anti-ultraviolet activities [ 25 , 26]. In this study, wood pulp/viscose fibers were chosen to produce the wetlace nonwoven fabric. For improving the antibacterial activity of fabric, HSDA was used to prepare $\mathrm{Ag}$ NPs to be fixed on the surface of wetlace nonwoven fabric.

\section{Experimental}

\subsection{Materials}

Wood pulp (23mm in length) and viscose fibers (38mm,1.6 Den) were purchased from Well Nonwoven Materials Co., Ltd., Nantong, China, and HSDA was prepared as described in our paper [25]. $\mathrm{AgNO}_{3}$ was purchased from Guoyao Chemical Reagent, China. S. aureus (ATCC 6538) and E. coli (ATCC 8099) were obtained from the Shanghai Luwei Technology Co., Ltd. (China).

\subsection{Preparation of the Silver Nanoparticles}

Equimolar (2mM) aqueous solution of $\mathrm{AgNO}_{3}$ and $2 \mathrm{~g} / \mathrm{L}$ HSDA were dissolved in deionized water at $40^{\circ} \mathrm{C}$ using a well-described procedure. The reaction mixture was slowly heated until reduction of $\mathrm{Ag}^{+}$to $\mathrm{Ag}^{0}$ was complete and formed brown silver colloid nanoparticles. The result silver colloidal solution was stored in a brown-glass container.

\subsection{Characterization of the Silver Nanoparticles}

The morphology and size of Ag NPs were characterized using a JEM-2100F transmission electron microscope (TEM) (JEOL, Japan). The ultraviolet-visible (UV-vis) spectra from 250 to $600 \mathrm{~nm}$ were recorded on a Hitachi UV-3010 spectrophotometer (Hitachi, Japan). X-ray diffraction (XRD) of silver nano hybrid particles was characterized with an Xpert pro diffractometer (Philips, Holland) utilizing a $\mathrm{Cu}$ $\mathrm{K} \alpha \mathrm{X}$-ray light source at a voltage of $40 \mathrm{kV}$ and a current of $30 \mathrm{~mA}$.

\subsection{Preparation and characterization of $\mathrm{Ag}$ NPs-coated wetlace nonwoven fabric}

The prepared Ag NPs solution was diluted with deionized water to keep the Ag content range from 50 to $200 \mathrm{mg} / \mathrm{L}$. To keep the gram weight of wetlace fabric around $60 \mathrm{~g} / \mathrm{m}^{2}$ and the strength of the wetlace fabric around $10 \mathrm{~N}, 7 \mathrm{~g}$ wood pulp and viscose fibers (70/30 in weight) were immersed in Ag NPs solutions for 30min at a water tank which contained a $0.1 \mathrm{~m}^{2}$ net curtain with the bath ratio of 1:50 [1, 2]. Beater was used to disperse the mixing fiber in Ag NPs solution. After the water in tank was drained, the homogenous fiber web was formed in net curtain, which were then bonded at 30 bars water pressure on both sides of the fabric. The Spunlace line used in this experiment was made by Feilong Co., Ltd, Suzhou, China.

The fabric was characterized and analyzed using Energy Dispersive Spectromete (EDS)(Carl Zeiss, EVO15), field emission scanning electron microcopy(FESEM)(scios dualbeam, Czechia). The silver content was measured by the inductively coupled plasma atomic emission spectroscopy (ICP-AES) method. (Varian, USA). The antimicrobial activity of silver-treated fabrics was tested against $E$. coli and $S$. aureu by using a shaking flask method according to $\mathrm{GB} / \mathrm{T}$ 20944.3-2008 (China). 0.75 g sample fabric, cut into small pieces in a size around $0.5 \times 0.5 \mathrm{~cm}^{2}$, was dipped into a flask containing $70 \mathrm{ml}$ of $0.3 \mathrm{mM}$ PBS (monopotassium phosphate, $\mathrm{pH} \approx 7.2$ ) culture solution with a cell concentration of $1 \times 10^{5} \mathrm{cfu} / \mathrm{ml}-4 \times 10^{5} \mathrm{cfu} / \mathrm{ml}$. The flask was then shaken at $150 \mathrm{rpm}$ on a rotary shaker at $24^{\circ} \mathrm{C}$ for $18 \mathrm{~h}$. From each incubated sample, $1 \mathrm{ml}$ of solution was taken, diluted and distributed onto an agar plate. All plates were incubated at $37^{\circ} \mathrm{C}$ for $24 \mathrm{~h}$, and the colonies formed were counted. The percentage reduction was determined as follows:

$$
\text { Reduction cfu }(\%)=\frac{C-A}{C} \times 100 \%
$$

Where, $C$ and $A$ are the bacterial colonies of the original fabrics and the treated fabrics, respectively [27, 28].

\section{Results and discussion}

\section{Characterization of $\mathrm{Ag} \mathrm{NP}$}

In this work, amino-functionalized Ag NPs were prepared in one-step by mixing $\mathrm{AgNO}_{3}$ aqueous solution and HSDA aqueous solution under vigorous stirring and heating conditions. With the increase in the stirring strength and heating time, the colorless and transparent solution gradually changed into light-yellow. The formation of sliver NPs can 
be observed by an UV-vis spectrophotometer, as shown in Figure 2. HSDA has a characteristic peak at $298 \mathrm{~nm}$, when the $\mathrm{AgNO}_{3}$ aqueous solution and HSDA aqueous solution were mixed. However, a new characteristic absorption of spherical silver nanoparticles appeared at $408 \mathrm{~nm}$. corresponding to the characteristic surface eplasmon resonance of metallic Ag NPs [29-31].

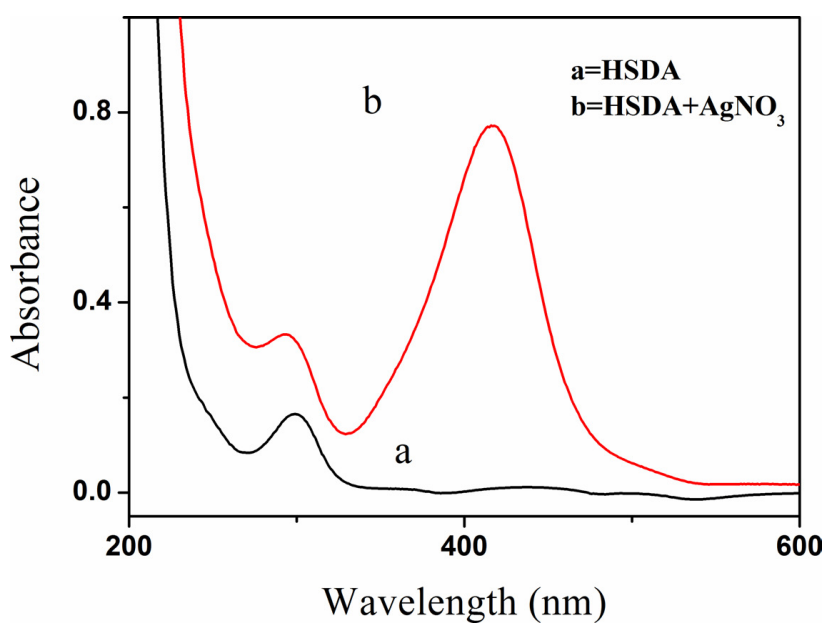

Figure 2: UV adsorption spectra of the Ag NPs solution.

The Ag NPs further confirmed by the TEM image shown in Figure 3(a) and Figure 3(b) revealed that the monodispersed Ag NPs had an average diameter of about $10 \mathrm{~nm}$ and a good dispersion. The observed large-scale HSDA capped Ag NPs with a regular spherical structure indicated HSDA has a good control of particle shape.
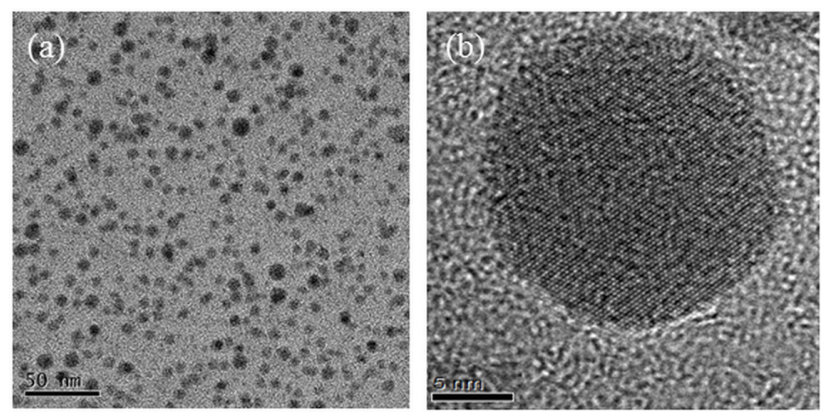

Figure 3: Characterization of the Ag NPs (a) TEM images of Ag NPs (b)HR TEM of Ag NPs.

To verify that silver nanoparticles were synthesized, the precipitated silver powders in the silver colloid were centrifuged, washed with methanol, and dried in the air for XRD measurement. The result was shown in Figure 4, the peaks at $2 \theta$ values are $38,44,64,78$, and 82 , represent-

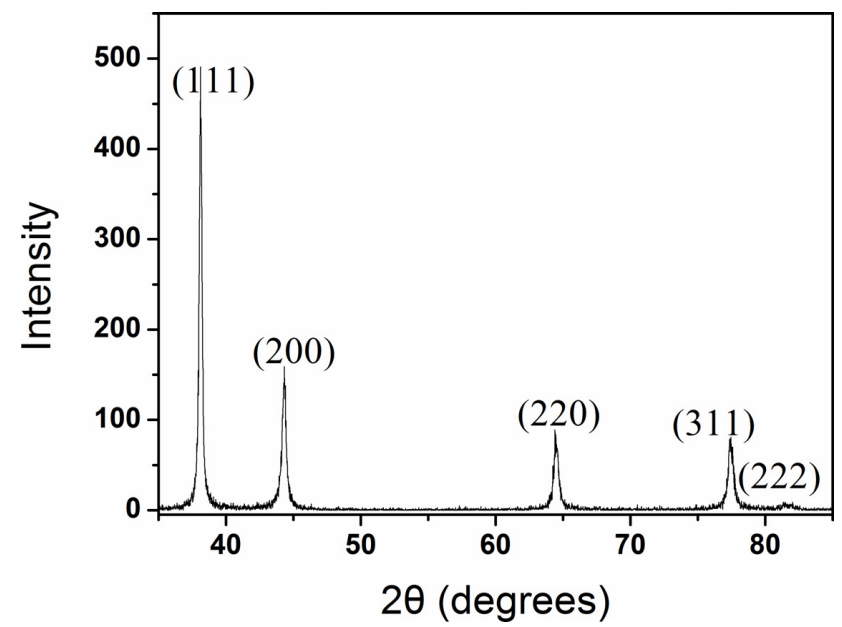

Figure 4: XRD spectrum of resulting Ag NPs.

ing the 111, 200, 220, 311, and 222 Braggs reflections of the face centered cubic structure of silver respectively, which are in excellent agreement with the values reported in literature [32-34].

As HSDA has a large number of amino functional groups with reducibility, which can reduce $\mathrm{Ag}^{+}$to $\mathrm{Ag}^{0}$ under a high temperature. HSDA can entrap Ag NPs into the confined inner cavity, preventing them from further aggregation. No noticeable change was found after the result nano-silver colloidal solutions had been stored more than one years.

\section{Preparation of Ag Np-coated wetlace nonwoven fabric}

The mechanism of prepare Ag Np-coated wetlace nonwoven fabric was shown in Scheme 1. Wood pulp/viscose fibers were immersed in the HSDA coated Ag NPs solution (Ag content range from 50 to $200 \mathrm{mg} / \mathrm{L}$ ). Ag NPs can be easily combined with cellulose fibers through intermolecular hydrogen bonds between amino end groups and pendent hydroxyl groups on cellulose fiber. Electrostatic bonding interactions between the negatively charged hydroxyl groups on cellulose fiber and positively charged amino end groups contributed to the enhancement of the stability and adhesion of HSDA capped Ag Nps on the surface of wetlace nonwoven $[28,35]$. In the reaction, Ag NPs can be coated on the surface of cellulose fiber, with the white cellulose fiber finally turning into yellow, and the light-yellow solution gradually turning into colorless and transparent.

To investigate the adsorption ability and content of Ag NPs on the fiber, the treated fabric was measured quantitatively with ICP-AES. As shown in Figure 5, the content 


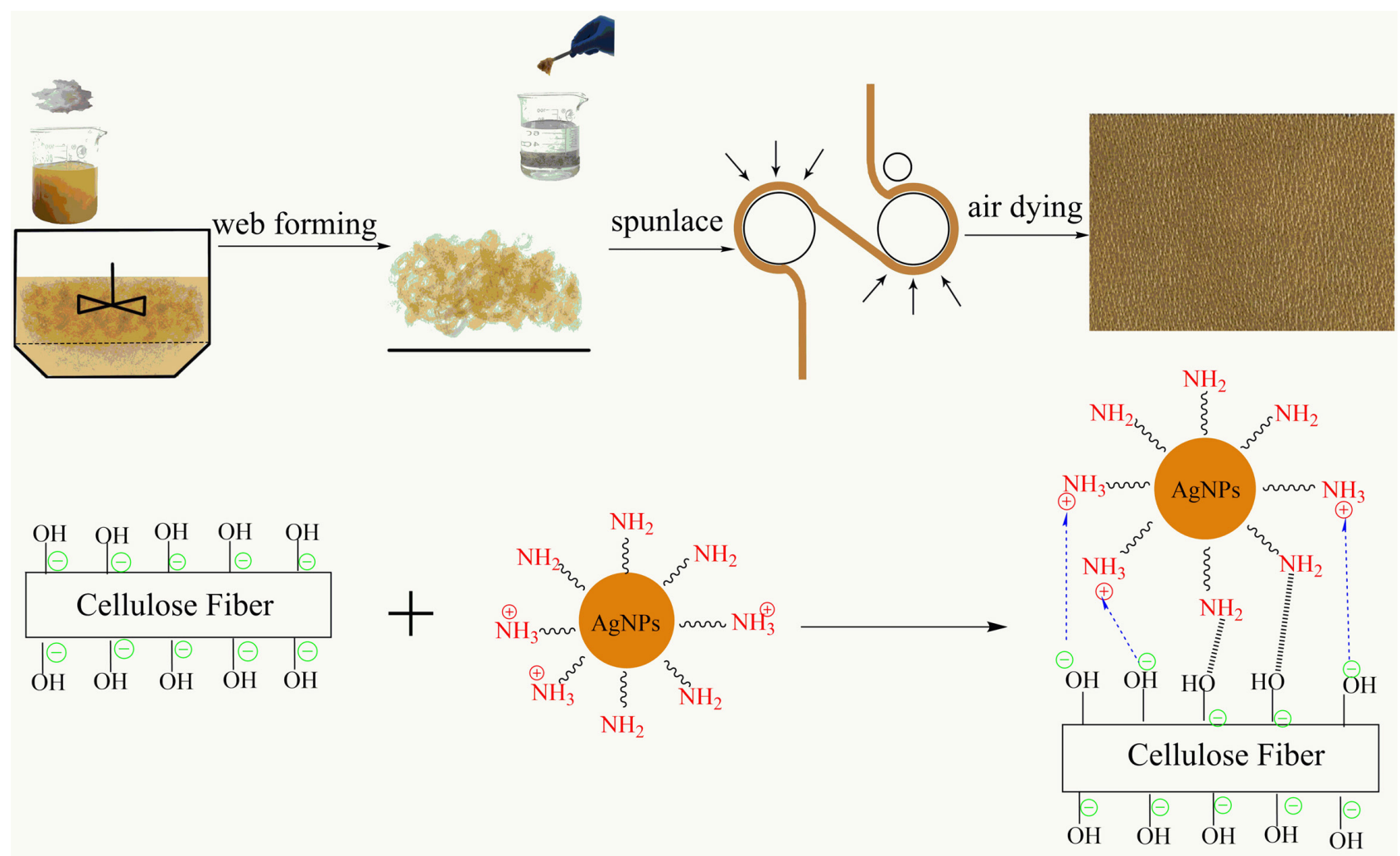

Scheme 1: Schematic illustration of Ag NPS on the surface of wetlace nonwoven fabric.

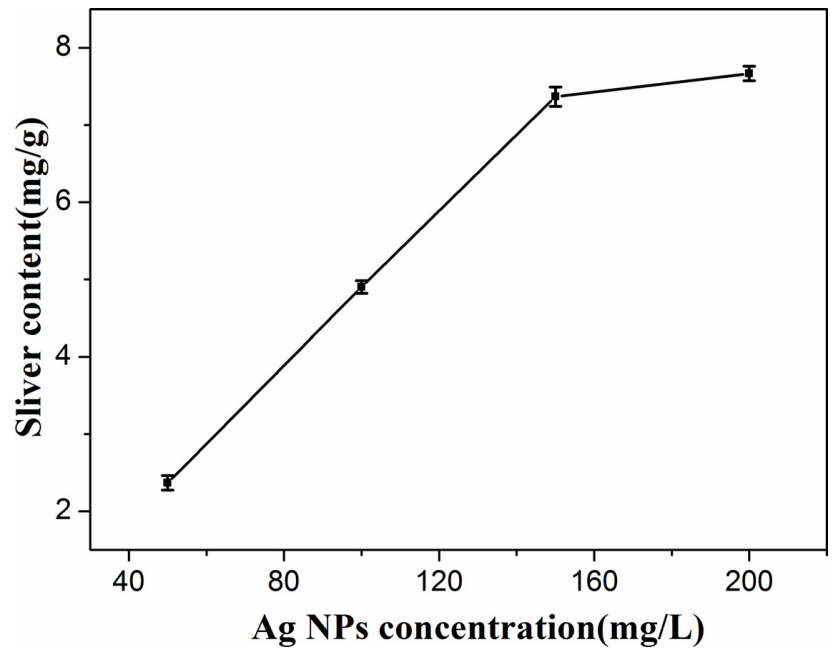

Figure 5: Silver content of Ag NPs coated fabric.

of Ag NPs were confirmed to be highly dependent on $\mathrm{Ag}$ NPs concentration. With increasing the concentration of Ag NPs from 50 to $200 \mathrm{mg} / \mathrm{L}$, the silver content of fibers increased proportionally from 2.5 to $7.5 \mathrm{mg} / \mathrm{g}$. This result revealed that the adsorption ability of Ag NPs on fibers was very strong. The maximum silver content of coated fibers can reach up to $7.5 \mathrm{mg} / \mathrm{g}$.

\section{SEM morphology and EDS Mapping of the AgNP-calcium alginate fibers}

The morphologies and distribution of Ag NPs coated on the surface of wood pulp fiber can be seen in Figure 6. Pure wood pulp fiber displayed a flat, dense and smooth surface, as shown in Figures 6(a). By contrast, the surface of Ag NPs-coated wood pulp fiber saw a uniform distribution of high-density white spots, as shown Figures 6(b), revealing a stronger adhesion of Ag NPs on the wood pulp fiber.

The chemical characteristics of the nano coating were further confirmed by the EDS mapping. Figure 7(a) showed additional Ag elements in the Ag NPs coated fabric, Cellulose fiber have $\mathrm{O}$ and $\mathrm{C}$ elements showed in Figure 7(b) and (C), Figure 7(d) showed the even distribution of Ag NPs on the fabric surfaces, which was in good agreement with FESEM measurements. This effect was mainly attributed to the strong adsorption between the wood pulp fiber and the amino groups capped on Ag NPs. 

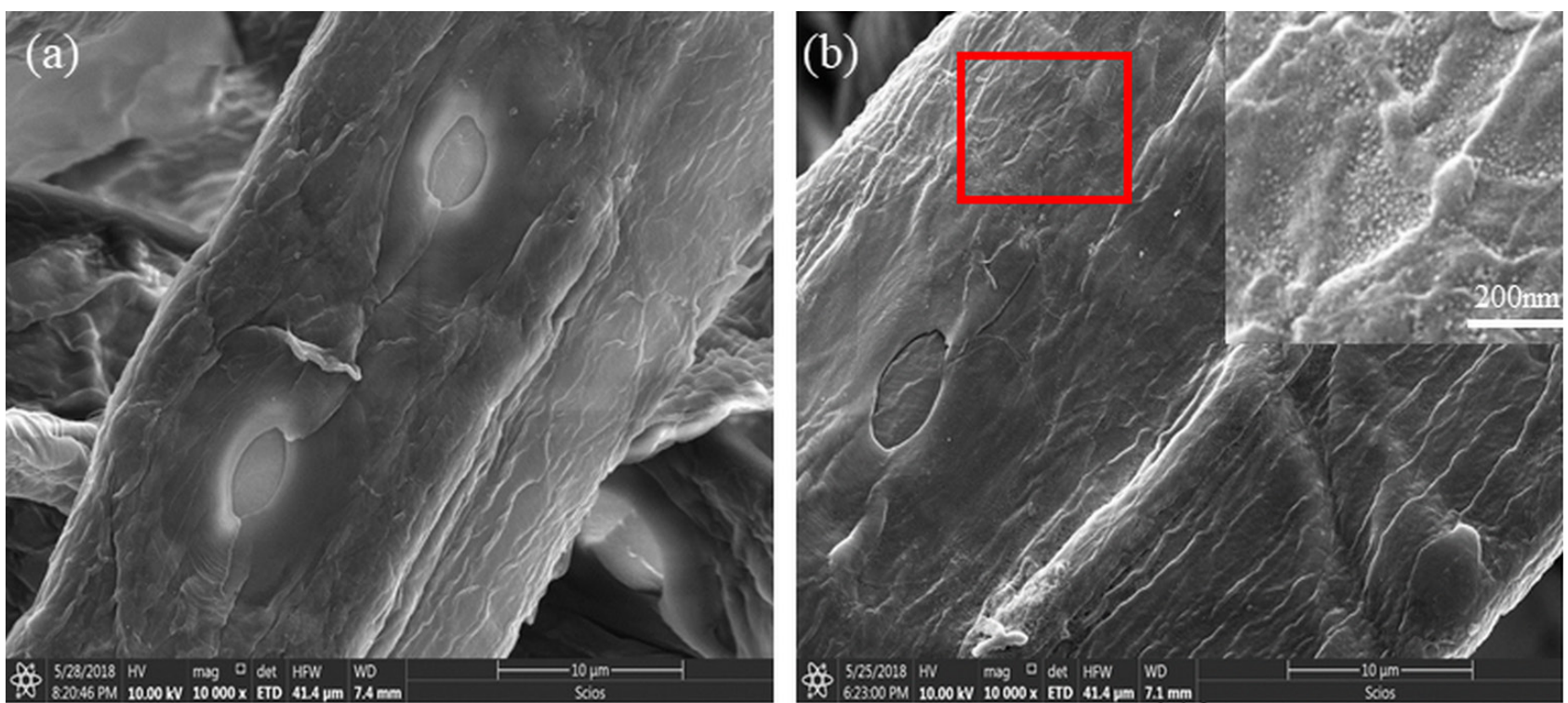

Figure 6: FESEM of (a) blank and (b) Ag NPs-coated wood pulp fiber(Ag content:7.5mg/g).
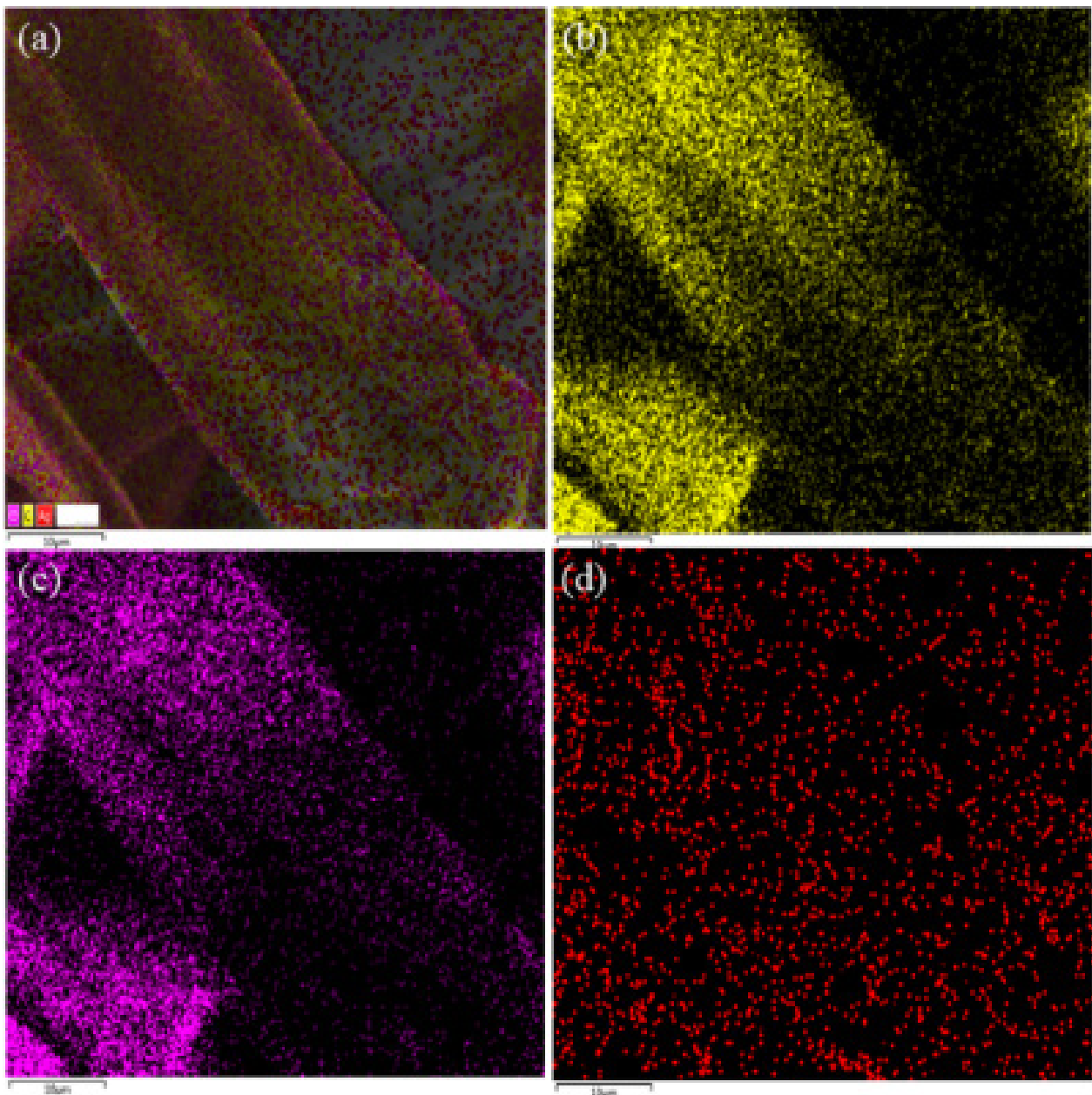

Figure 7: EDS mapping of (a) elements on wetlace nonwoven fabric and(b) C on fabric(c) 0 on fabric (d) Ag on fabric(Ag content: $7.5 \mathrm{mg} / \mathrm{g})$. 
Table 1: Antibacterial activity of wetlace nonwoven fabrics

\begin{tabular}{cccccc}
\hline Sample & $\begin{array}{c}\text { Silver content } \\
(\mathrm{mg} / \mathrm{g})\end{array}$ & $\begin{array}{c}c \\
\text { Surviving cells } \\
(\mathrm{CFU} / \mathrm{mL})\end{array}$ & Reduction $(\%)$ & $\begin{array}{c}\text { E. coli } \\
\text { Surviving cells } \\
(\mathrm{CFU} / \mathrm{mL})\end{array}$ & Reduction (\%) \\
\hline Wetlcae fabric & 0 & $1.58 \times 10^{6}$ & - & $2.5 \times 10^{5}$ & - \\
HSDA treated fabric & 0 & $1.05 \times 10^{6}$ & 50.4 & $1.4 \times 10^{5}$ & 44 \\
Ag NPs fabric & 2.5 & $1.2 \times 10^{4}$ & 99.24 & $1.5 \times 10^{3}$ & 99.4 \\
& 5 & $2.3 \times 10^{2}$ & 99.98 & $2.1 \times 10^{2}$ & 99.91 \\
& 7.5 & 3 & 100 & 2 & 100 \\
& 7.52 & 0 & 100 & 0 & 100 \\
\hline
\end{tabular}

\section{Antibacterial activity of Ag NPs coated wetlace nonwoven fabrics}

The antibacterial activity of wetlace nonwoven fabric was qualitatively evaluated by the shake-flask method using gram-negative $E$. coli and gram-positive $S$. aureus bacteria cells. Blank and HSDA treated fabric as contrast sample, the results of which were presented in Table 1. Cellulose fibers did not show antibacterial activities against $S$. aureus or E. coli, indicating the fiber itself was insufficient to inhibit the bacterial growth. As the Cationic group in HSDA, HSDA treated fibers showed antibacterial activities, the reduction rates of $S$. aureus and $E$. coli can reach about $50 \%$. By contrast, Ag NP-coated fibers exhibited excellent antibacterial activities. The bacterial reduction rates of both $S$. aureus and $E$. coli can reach above $99 \%$, even at the minimum silver content $(2.5 \mathrm{mg} / \mathrm{g})[25,36]$.

\section{Conclusions}

HSDA-capped Ag NPs were prepared in one-step by mixing $\mathrm{AgNO}_{3}$ and $\mathrm{HSDA}$ aqueous solutions under heating condition. HSDA-capped AgNPs were endowed with positive charges and high binding affinity towards wood pulp fiber. The Ag NPs-coated wetlace nonwoven fabric was formed by wet-laid and spunlace process. Both SEM and EDS analysis showed that high-density Ag NPs were well distributed on the surface of wetlace nonwoven. Also, Ag NPs-coated fabric showed excellent antibacterial activity against both $S$. aureus and E. coli.

Acknowledgement: This work was supported by the the National Science Foundation (Grant No. 51503105, 51803094), National Key Research and Development Program of China (2016YFB0303100)

\section{References}

[1] Zhang Y, Deng C, Wang Y, Huang C, Zhao Y, Jin X. A new dispersible moist wipe from wetlaid/spunlace nonwoven: Development and characterization. J Ind Text 2018. DOI: /10.1177/15 28083718757524

[2] Zhang Y, Zhao Y, Latifi M, Wang R, Jin X. Investigation of the mechanical and dispersible properties of wood pulp/Danufil wetlaid nonwovens with/without hydroentanglement. J. Text. I. 2017, 109, 647-655.

[3] Sun KC, Sahito IA, Noh JW, Yeo SY, Im JN, Yi SC, Kim YS, Jeong SH. Highly efficient and durable dye-sensitized solar cells based on a wet-laid PET membrane electrolyte. J. Mater. Chem. A. 2016, 4, 458-465

[4] Wang Y, Zhan HY, Hu J, Liang Y, Zeng S. Wet-laid non-woven fabric for separator of lithium-ion battery. J. POWER. SOURCES. 2009, 189, 616-619.

[5] Latifi M, Tafreshi H V, Pourdeyhimi B. A note on an optical method to evaluate fiber dispersion in wet-laid nonwoven process. TEXT. RES. J. 2008, 78, 518-523.

[6] Maity S, Gon DP, Paul P. A review of flax nonwovens: Manufacturing, properties, and applications. J. NAT. FIBERS. 2014, 11, 365-390.

[7] Doh SJ, Lee JY, Lim DY, Im JN.Manufacturing and analyses of wet-laid nonwoven consisting of carboxymethyl cellulose fibers. FIBER POLYM. 2013,14, 2176-2184.

[8] Wood AT, Everett D, Budhwani KI, Dickinson B, ThomasV. Wetlaid soy fiber reinforced hydrogel scaffold: Fabrication, mechanomorphological and cell studies. Mat. Sci. Eng C. 2016,63,308316.

[9] Yoon MJ, Doh SJ, Im JN. Preparation and characterization of carboxymethyl cellulose nonwovens by a wet-laid process. FIBER POLYM. 2011,12,247-251.

[10] Uddin ME, Layek RK, Kim HY, Kim NH, Hui D, Lee JH. Preparation and enhanced mechanical properties of non-covalentlyfunctionalized graphene oxide/cellulose acetate nanocomposites. COMPOS. PART. B-ENG, 2016, 90, 223-231.

[11] Rai M, Birla S, Ingle AP, Gupta I, Gade A, Abd-Elsalam K, et al. Nanosilver: an inorganic nanoparticle with myriad potential applications. Nanotechnol Rev. 2014, 3, 281-309.

[12] Sawhney APS, Condon B, Singh K, Pang S-S, Li G, Hui D. Modern Applications of Nanotechnology in Textile TEXT. RES. J. 2008, 78, 731-739 
[13] Zhang CY, Hao R, Zhao B, Fu Y, Zhang H, Moeendarbari S, Pickering CS, Hao YW, Liu Y. Graphene oxide-wrapped flower-like sliver particles for surface-enhanced Raman spectroscopy and their applications in polychlorinated biphenyls detection. Appl Surf Sci. 2017, 400, 49-56.

[14] Yu Q, Xu X, Wang C, Ma Y, Hui D, Zhou Z. Remarkably improvement in antibacterial activity by synergistic effect in n-Cu@ T-ZnO nanocomposites. COMPOS. PART. B-ENG. 2017, 110, 32-38.

[15] Xu X, Chen D, Yi Z, Jiang M, Wang L, Zhou Z, Hui D. Antimicrobial mechanism based on $\mathrm{H}_{2} \mathrm{O}_{2}$ generation at oxygen vacancies in ZnO crystals. Langmuir. 2013, 29, 5573-5580.

[16] Roy K, Sarkar CK, Ghosh CK. Antibacterial mechanism of biogenic copper nanoparticles synthesized using Heliconia psittacorum leaf extract. Nanotechnol Rev. 2016, 5, 529-536.

[17] Eskandari-Nojedehi M, Jafarizadeh-Malmiri H, Rahbar-Shahrouz J. Optimization of processing parameters in green synthesis of gold nanoparticles using microwave and edible mushroom (Agaricus bisporus) extract and evaluation of their antibacterial activity. Nanotechnol Rev. 2016, 5. 537-548.

[18] Straumal BB, Pontikis V, Kilmametov AR, Mazilkin AA, Dobatkin SV, Baretzky B. Competition between precipitation and dissolution in $\mathrm{Cu}-\mathrm{Ag}$ alloys under high pressure torsion. Acta Mater. 2017, 122, 60-71.

[19] Xu S, Song J, Zhu C, Morikawa H. Graphene oxide-encapsulated Ag nanoparticle-coated silk fibers with hierarchical coaxial cable structure fabricated by the molecule-directed self-assembly. Mater Lett. 2017, 188, 215-219.

[20] Giannossa LC, Longano D, Ditaranto N, Nitti MA, Paladini F, Pollini M, Cioffi N. Metal nanoantimicrobials for textile applications. Nanotechnol Rev. 2013, 2, 307-331.

[21] Rai M, Birla S, Ingle AP, Gupta I, Gade A, Abd-Elsalam K, Duran N. Nanosilver: an inorganic nanoparticle with myriad potential applications. Nanotechnol Rev. 2014, 3, 281-309.

[22] Chen CY, Chiang CL. Preparation of cotton fibers with antibacterial silver nanoparticles. Mater. Lett. 2008, 62, 3607-3609.

[23] Xue CH, Chen J, Yin W, Jia ST, Ma JZ. Superhydrophobic conductive textiles with antibacterial property by coating fibers with silver nanoparticles. Appl. Surf. Sci. 2012, 258, 2468-2472.

[24] Karwowska E. Antibacterial potential of nanocomposite-based materials a short review. Nanotechnol Rev. 2017, 6, 243-254.

[25] Zhang G, Liu Y, Morikawa H, Chen Y. Application of ZnO nanoparticles to enhance the antimicrobial activity and ultraviolet protective property of bamboo pulp fabric. Cellulose. 2013, 20, 18771884.
[26] Zhang F, Chen Y, Lin H, et al. Synthesis of an aminoterminated(6) hyperbranched polymer and its application in reactive dyeing on cotton as a salt-free dyeing auxiliary. Color Technol. 2007; 123, 351-357

[27] Lee HJ, Yeo SY, Jeong SH. Antibacterial effect of nanosized silver colloidal solution on textile fabrics. J. Mater. Sci. 2003, 38, 2199 2204.

[28] Xu S, Zhang F, Song J, Kishimoto Y, Morikawa H. Preparation of silver nanoparticle-coated calcium alginate fibers by hyperbranched poly(amidoamine)-mediated assembly and their antibacterial activity. TEXT. RES. J. 2015, 86, 878-886.

[29] Zhang F, Wu X, Chen Y, Lin H. Application of silver nanoparticles to cotton fabric as an antibacterial textile finish. Fibers Polym. 2009, 10, 496-501.

[30] Ankamwar B, Kamble V, Sur UK, Santra C. Spectrophotometric evaluation of surface morphology dependent catalytic activity of biosynthesized silver and gold nanoparticles using UV-vis spectra: A comparative kinetic study.Appl Surf Sci. 2016, 366, 275-283.

[31] Nair S, Laurencin CT. Silver nanoparticles: synthesis and therapeutic applications. J. Biomed. Nanotechnol. 2007, 3, 301-316.

[32] Kakati N, Mahapatra SS, Karak N. Silver nanoparticles in polyacrylamide and hyperbranched polyamine matrix. J. Macromol. Sci Part A: Pure Appl. Chem. 2008, 45, 658-663.

[33] Zhang DS, Liu XY, Li JL, Xu HY, Lin H, Chen YY. Design and Fabrication of a New Class of Nano Hybrid Materials based on Reactive Polymeric Molecular Cages. Langmuir. 2013, 29, 11498-505.

[34] Zhu Y, Wang X, Guo W. Sonochemical synthesis of silver nanorods by reduction of sliver nitrate in aqueous solution. ULTRASON SONOCHEM. 2010, 17, 675-679.

[35] Xu S, Chen S, Zhang F. Preparation and controlled coating of hydroxyl-modified silver nanoparticles on silk fibers through intermolecular interaction-induced self-assembly. MATER DESIGN. 2016, 95, 107-118.

[36] T. Bhuyan, M. Khanuja, R. Sharma, S. Patel, M.R. Reddy, S. Anand, A. Varma, A comparative study of pure and copper ( $\mathrm{Cu}$ )-doped $\mathrm{ZnO}$ nanorods for antibacterial and photocatalytic applications with their mechanism of action. J Nano Res. 2015, 17, 288. 